\title{
Negative Prognostic Implication of TERT Promoter Mutations in Human Papillomavirus-Negative Tonsillar Squamous Cell Carcinoma Under the New 8th AJCC Staging System
}

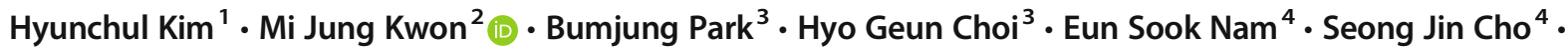 \\ Kyueng-Whan $\mathrm{Min}^{5} \cdot$ Eun Soo Kim ${ }^{6} \cdot$ Hee Sung Hwang ${ }^{7}$. Mineui Hong ${ }^{8} \cdot$ Taeryool Koo $^{9} \cdot$ Hyo Jung Kim ${ }^{10}$
}

Received: 17 June 2020 / Accepted: 19 August 2020 / Published online: 5 September 2020

(C) The Author(s) 2020

\begin{abstract}
Telomerase reverse transcriptase gene promoter (TERTp) mutation is a potential candidate for pathogenesis and therapeutic target of tonsillar squamous cell carcinomas (TSCCs) in association with human papillomavirus (HPV). Their clinical relevance has not been validated under the new 8th American Joint Committee on Cancer (AJCC) staging system. We analyzed real-time peptide nucleic acid-mediated PCR and sequencing methods (TERTp mutation) and real-time PCR-based assay (HPV) in 80 surgically resected TSCCs. The 8 th edition staging system improved the stratification of the early and advanced stages and between T or $\mathrm{N}$ categories for overall survival over the 7th edition. TERTp mutation was found in $7.5 \%$, and HPV in $80.0 \%$ of the patients. The majority $(83.3 \%)$ of TERTp mutation cases were HPV-positive TSCCs. Applying the 8th edition staging system, TERTp mutation was an independent factor of poor prognosis for disease-free survival (DFS) in TSCC patients, supporting the clinical significance of TERTp mutation in tonsil cancer. TERTp mutations were also negatively correlated with overall survival and DFS in HPV-negative TSCCs. Conclusively, TERTp mutation provides negative prognostic impact on survival of surgically managed tonsil cancers staged with the AJCC 8th edition.
\end{abstract}

Keywords Tonsil $\cdot$ Squamous cell carcinoma $\cdot$ Human papillomavirus $\cdot$ Head and neck cancer $\cdot$ Prognosis

\section{Abbreviations}

TSCC Tonsillar squamous cell carcinoma

HPV Human papillomavirus

Mi Jung Kwon

mulank@hanmail.net

1 Department of Pathology, Dongtan Sacred Heart Hospital, 7, Keunjaebong-gil, Hwaseong-si, Gyeonggi-do 18450, Republic of Korea

2 Department of Pathology, Hallym University Sacred Heart Hospital, Hallym University, 22, Gwanpyeong-ro 170beon-gil, Dongan-gu, Anyang-si, Gyeonggi-do 14068, Republic of Korea

3 Department of Otorhinolaryngology-Head and Neck Surgery, Hallym University Sacred Heart Hospital, Hallym University College of Medicine, Anyang, Republic of Korea

4 Department of Pathology, Kangdong Sacred Heart Hospital, Hallym University College of Medicine, Seoul 134-701, Republic of Korea

5 Department of Pathology, Hanyang University Guri Hospital, Hanyang University College of Medicine, Kyoungchun-ro 153, Guri-si, Gyeonggi-do 11923, Republic of Korea
SCC Oropharyngeal squamous cell carcinoma

AJCC American Joint Committee on Cancer

TERTP TERT promoter
6 Department of Radiology, Hallym University Sacred Heart Hospital, Hallym University College of Medicine, Anyang, Republic of Korea

7 Department of Nuclear Medicine, Hallym University Sacred Heart Hospital, Hallym University College of Medicine, Anyang, Republic of Korea

8 Department of Pathology, Kangnam Sacred Heart Hospital, Hallym University College of Medicine, Daerim 1-Dong, Yeongdeungpo-gu, Seoul 150-950, Republic of Korea

9 Department of Radiation Oncology, Hallym University Sacred Heart Hospital, Hallym University College of Medicine, Anyang, Republic of Korea

10 Department of Hematological Oncology, Hallym University Sacred Heart Hospital, Hallym University College of Medicine, Anyang, Republic of Korea 
OS Overall survival

DFS Disease-free survival

BOT Base of tongue
AJCC staging system compared with the 7th edition, with variation in patient location and therapy.

\section{Patients and Methods}

\section{Introduction}

Tonsillar squamous cell carcinomas (TSCCs) account for 70$80 \%$ of the oropharyngeal cancers most prevalent for human papillomavirus (HPV) [1-3]. In oropharyngeal squamous cell carcinomas (SCCs), HPV is associated with better prognosis and response to radiochemotherapy compared with HPVnegative oropharyngeal SCCs $[3,4]$. Tonsils are the subsite of oropharyngeal cancers with the highest HPV-positive rate $[2,3]$. The 5 -year survival in early cases has been reported to be $>90 \%$, which decreases to $<20 \%$ in advanced tonsil cancer $[1-3,5]$. Both primary surgery and radiotherapy/ chemotherapy are effective treatments for TSCCs [4]; however, treatment failures can develop unexpectedly. The 8th edition of the American Joint Committee on Cancer (AJCC) staging system for oropharyngeal cancer incorporates HPV infection and extranodal extension [6], but it is unclear whether those result in better stratification of Korean patients, as the area has relatively low incidence of oropharyngeal cancer [7-9]. Because risk stratification, prognosis prediction, treatment selection, and follow-up strategies often depend on the AJCC system, validation of staging is crucial.

The TERT promoter (TERTp), a critically important regulatory element for telomerase expression harboring binding sites for a number of transcriptional activators and repressors, contributes to increased telomerase activity that leads to immortalization of cells, which is one of the hallmarks of cancer $[10,11]$. Two mutually exclusive $\mathrm{G}-\mathrm{A}$ mutations at nucleotide -124 and -146 within the core promoter region of TERT gene occur as a pathogenic mutation in human malignancies [12], which are also driver mutations in head and neck SCCs [13-17]. The TERTp mutation, alone and with the HPV oncogenes, plays an important role in oral and uterine cervical SCCs $[14,18,19]$. Two viral oncogenes, E6 and E7, expressed by high-risk HPV-associated cancers, affect the oncogenic pathway related to cellular immortalization, typically activating telomerase expression $[18,20,21]$. Although previous studies examined multiple subsites of oral or oropharyngeal cancers, the frequencies of TERTp mutation in tonsil cancers and the association to HPV have rarely been investigated in the series of their studies [22, 23]. Furthermore, the revised 8th AJCC staging system in terms of oropharyngeal cancers with or without HPV has not been validated in the Far East Asian cohort data, specifically on tonsil cancers.

Here, we investigated TERTp mutation, HPV infection, and clinicopathological characteristics in 80 Korean primary TSCC patients. We sought to validate the 8 th edition of the

\section{Patients}

Formalin-fixed, paraffin-embedded (FFPE) tissues were obtained from 80 TSCC patients who underwent primary resection, with no prior treatment and complete medical records at our institution between 1997 and 2018. Clinical information was analyzed using medical records and radiological results. Heavy smoking was defined as $>20$ pack-years [6]. Alcohol consumption was defined as $>14$ drinks/week [6]. Of these 80 patients, 11 patients underwent postoperative radiotherapy, 2 patients had chemotherapy, and 39 patients had chemoradiotherapy following the surgical resection. The remaining 28 patients were treated with surgery alone. Radiation doses ranged from 5040 to $7200 \mathrm{cGy} / 36$ fractions over 8 weeks.

Diagnosis and histological differentiation were evaluated according to the World Health Organization classification [1]. Patients were re-staged according to the 8th editions of the AJCC/UICC TNM classification [6]. The study protocol was approved by Sacred Heart Hospital Institutional Review Board (No. 14-2-57) and performed in accordance with the relevant guidelines and regulations (Declaration of Helsinki). Informed consent was obtained from the patients and from the next of kin (deceased patients) before enrollment in the study.

\section{DNA Extraction and Detection of TERT Promoter Mutation}

Genomic DNA was extracted from $10-\mu$ m-thick sections of 10\% neutral FFPE tumor tissue blocks using Maxwell 16 FFPE Tissue LEV DNA Purification Kit for DNA (Promega, USA). TERTp mutations (C250 and C228) were identified using the PNAClamp ${ }^{\text {TM }}$ TERT mutation detection kit (PANAGENE, Daejeon, South Korea [10]. Subsequently, the TERTp mutation analyses were also confirmed by directional sequencing of PCR fragments amplified from genomic DNA. The primers used for TERTp were as follows [24]: forward, 5'-AGTGGATTCGCGGGCACAGA-3', and reverse, 5'-AGCACCTCGCGGTAGTGG-3', which amplified a 346 bp fragment. PCR amplification was carried out in a reaction volume of $30 \mu \mathrm{l}$ containing $100 \mathrm{ng}$ of template DNA, $10 \times$ PCR buffer, $0.25 \mathrm{mM}$ dNTPs, 10 pmol primers, and 1.25 U Taq DNA polymerase (Solgent, Korea). The thermal cycling conditions were as follows: denaturation at $95{ }^{\circ} \mathrm{C}$ for $3 \mathrm{~min}$, followed by 10 cycles of $95^{\circ} \mathrm{C}$ denaturation for $30 \mathrm{~s}$, $60{ }^{\circ} \mathrm{C}$ annealing for $30 \mathrm{~s}$, and $68^{\circ} \mathrm{C}$ elongation for $1 \mathrm{~min}$. This was followed by 30 cycles under the same settings, with the elongation step modified to continue for an additional $5 \mathrm{~s}$ each 
cycle. PCR was completed with final elongation at $68^{\circ} \mathrm{C}$ for 7 min. PCR products were electrophoresed on $2 \%$ agarose gels and purified with a Solgent PCR purification kit (Solgent). All amplification products were sequenced bidirectionally using an automated sequencer (ABI 3130xl; Applied Biosystems, Foster City, CA, USA) using the BigDye Terminator v1.1 kit (Applied Biosystems) and the appropriate forward and reverse primers.

\section{Detection of HPV}

HPV status was evaluated by PANA RealTyper HPV genotyping kit and PANA RealTyper HPV screening kit (PANAGENE). This kit, approved for clinical use in Korea, detects a total of $40 \mathrm{HPV}$ genotypes including 20 high-risk genotypes $(16,18,26,31,33,35,39,45,51,52,53,56,58$, $59,66,68,69,70,73$, and 82), 2 low-risk genotypes (6 and 11 ), and 18 other genotypes. Briefly, real-time PCR assays were performed in a $25 \mu \mathrm{l}$ reaction mixture containing $19 \mu \mathrm{l}$ of HPV mix, $1 \mu \mathrm{l}$ of Taq DNA polymerase, and $5 \mu \mathrm{l}$ of extracted DNA, positive control, or negative control. PCR was performed using the following conditions: 1 cycle of incubation at $50{ }^{\circ} \mathrm{C}$ for $2 \mathrm{~min}$ and Taq activation at $95{ }^{\circ} \mathrm{C}$ for $15 \mathrm{~min} ; 45$ cycles of denaturation at $95^{\circ} \mathrm{C}$ for $15 \mathrm{~s}$, annealing at $55^{\circ} \mathrm{C}$ for $45 \mathrm{~s}$, and extension at $72{ }^{\circ} \mathrm{C}$ for $15 \mathrm{~s}$; and a melting curve step at $95{ }^{\circ} \mathrm{C}$ for $5 \mathrm{~min}, 35^{\circ} \mathrm{C}$ for $5 \mathrm{~min}$, followed by increase in temperature from $35^{\circ} \mathrm{C}$ to $80^{\circ} \mathrm{C}$ for $5 \mathrm{~min}$, with a gradual increment of $0.5^{\circ} \mathrm{C}$ (every $5 \mathrm{~s}$ ) to achieve fluorescence in all four channels (FAM, HEX or VIC, ROX, and Cy5).

\section{Statistical Analysis}

Correlations between the TERTp mutation and clinicopathological variables were assessed using the Chi-squared test or two-tailed Fisher's exact test. Factors found to be significant in univariate analysis were included in subsequent binary logistic regression analysis to identify independent variables associated with TERTp mutation. Survival analyses were performed using the Kaplan-Meier method and were compared using a log-rank test. Overall survival (OS) was defined as the interval from the first day of surgery until death. Disease-free survival (DFS) was defined as the interval from the first day of surgery until tumor recurrence. OS and DFS were analyzed until February 2019. Univariate and multivariate analyses using the Cox proportional hazard regression model were applied to determine the hazard ratio (HR) and $95 \%$ confidence intervals $(\mathrm{CI})$ for specific variables related to OS and DFS. SPSS version 18 (SPSS Inc., Chicago, IL, USA) was used for all statistical analyses. $P$ values $<0.05$ were considered statistically significant.

\section{Results}

\section{Comparisons Between the AJCC 8th and 7th Edition Staging Systems}

According to the 8 th edition staging system, 18 (22.5\%) tumors were classified as T1, $31(38.8 \%)$ as T2, $20(25.0 \%)$ as $\mathrm{T} 3$, and $11(13.7 \%)$ as $\mathrm{T} 4$. Of the 80 patients, 17 $(21.3 \%)$ were categorized as N0, 37 patients $(46.3 \%)$ as $\mathrm{N} 1,11(13.7 \%)$ as $\mathrm{N} 2$, and $15(18.7 \%)$ as N3. Combining the $\mathrm{T}$ and $\mathrm{N}$ categories, the overall stages of 31 patients were diagnosed as stage I (38.8\%), $18(22.5 \%)$ as stage II, $11(13.7 \%)$ as stage III, and $20(25.0 \%)$ as stage IV. The median follow-up period was 64 months (range, 3136 months). The 5-year OS and DFS rates were 53.2\% and $43.8 \%$, respectively.

We performed Kaplan-Meier survival analyses of OS in 80 patients who had previous TNM information according to AJCC 8th vs. AJCC 7th staging system (Fig. 1). We compared the $\mathrm{T}$ category, $\mathrm{N}$ category, and overall stages assigned by the 8th and 7th editions of the AJCC staging system. As shown in Fig. 3, the 7th edition of the AJCC staging system performed poorly with respect to the discrimination and stratification of $\mathrm{N}$ category and overall stages $(P=0.063$ and $P=0.471$, respectively). Only the $\mathrm{T}$ category was well discriminated according to clinical outcomes $(P=0.043)$. In contrast, the 8th edition provided statistically significant stratification for the $\mathrm{T}$ category, $\mathrm{N}$ category, and overall staging $(P=0.041, P<0.001$, and $P<0.001$, respectively). Therefore, the 8 th edition was applied in our study.

\section{HPV and TERTp Mutation}

HPV was identified in 64 tumors $(80.0 \%)$ analyzed by realtime HPV genotyping kit. All 80 cases were interpretable. There were only high-risk HPV genotypes including HPV $16(54 / 64,84.4 \%)$, HPV 18 (4/64, 6.2\%), HPV 58 (1/64, 1.6\%), and concurrent HPV 16 and HPV 18 (5/64, 7.8\%) (Fig. 2a-d). We also analyzed the incidence of HPV in TSCCs during the last 20 years (Fig. 2e). The HPV-positive rates in those tonsil cancers decreased from $88.9 \%(16 / 18)$ in $2001-2005$ to $79.6 \%$ (29/49) in 2006-2010 and $69.2 \%$ (9/13) in 2011-2019.

The real-time quantitative PCR with PNA-mediated clamping method identified six mutations at position -124 within TERTp in 80 TSCC patients (Fig. 2f). No TERTp mutation at position -146 was identified. To confirm these results, direct sequencing was repeatedly performed and consistently identified TERTp mutations in $6(7.5 \%)$ of 80 tumor samples. The observed point mutations were hot spot nucleotide changes $\mathrm{G}$ to $\mathrm{A}$ at position - 124 within TERTp in 6 cases (Fig. 2g). 
a

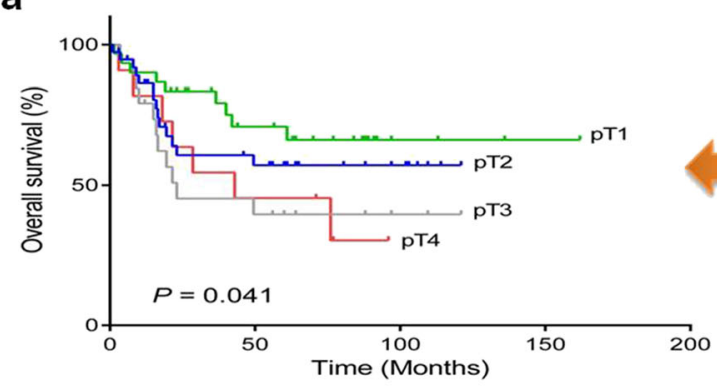

C

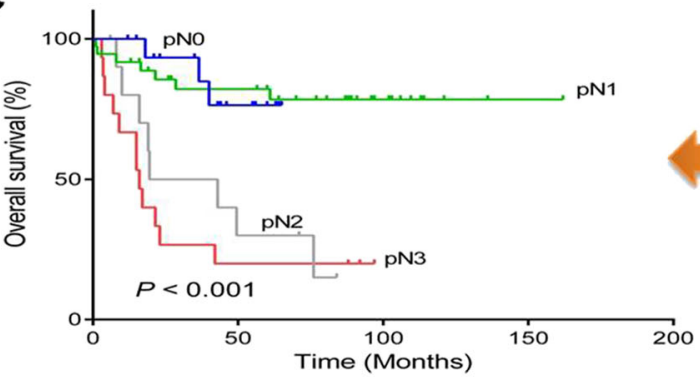

e

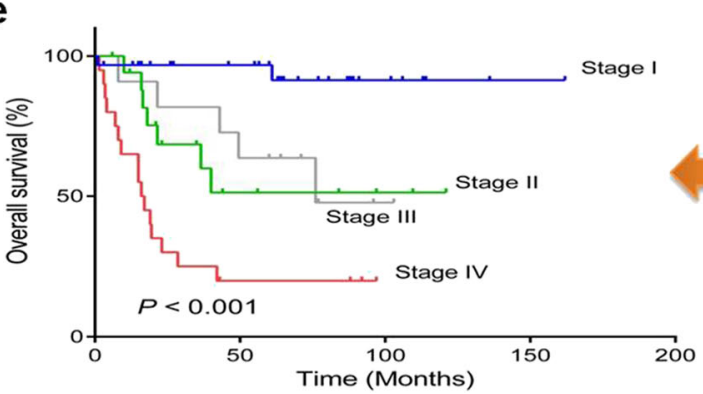

b

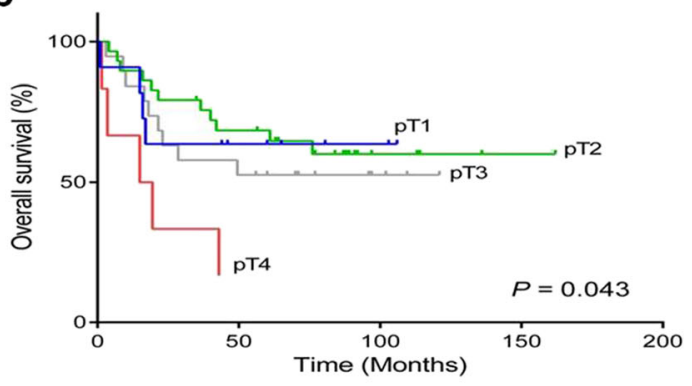

d

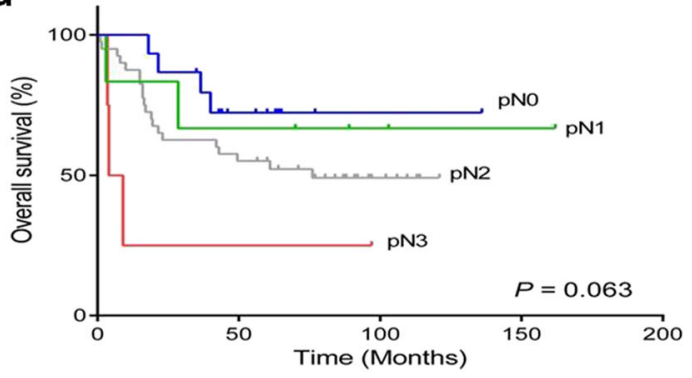

f

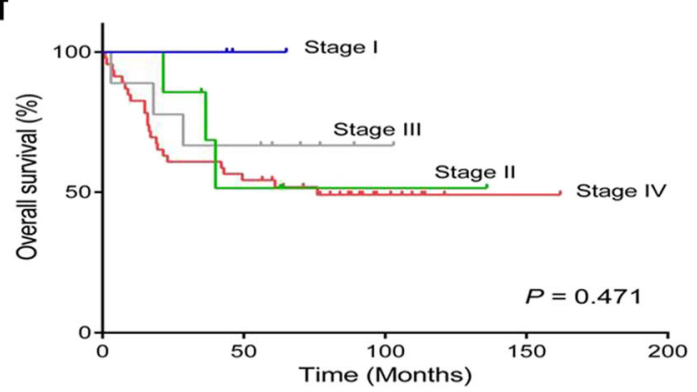

Fig. 1 Overall survival analyses of tonsillar squamous cell carcinomas according to newly revised pT category (a), pN category (c), and AJCC stage 8th (e) compared with previous $\mathrm{pT}$ (7th edition) (b), pN (7th edition) (d), and AJCC stage 7th (f)

We analyzed the associations of HPV or TERTp mutation with clinical and pathological features of 80 TSCCs (Table 1). The presence of HPV was more frequently associated with younger age $(\leq 60$ years $)(P=$ $0.010)$, low alcohol consumption $(P=0.021), \mathrm{pN}$ positive status $(P<0.001)$, lower AJCC stage $(P=$ $0.020)$, and presence of ipsilateral lymph node metastasis $(P=0.004)$. HPV positivity was not associated with TERTp mutation. There were no statistical associations between TERTp mutation and clinicopathologic features of TSCCs.

Coexistence of HPV and TERTp mutation occurred in 5 cases $(6.3 \%)$ of 80 TSCCs: a total of 5 cases $(83.3 \%)$ among the 6 TERTp mutations were in HPV 16-positive tonsil cancers and one TERTp mutated tumor was HPVnegative. TSCCs showed the most frequently HPV-positive/TERTp-wild-type $(n=59,73.7 \%)$, followed by HPV-negative/TERTp-wild-type $(n=15,18.8 \%)$, HPVpositive/TERTp-mutated $(n=5,6.2 \%)$, and HPV-negative/TERTp-mutated ( $n=1,1.3 \%)$ (Fig. 3a).

\section{Prognostic Correlation of TERTp Mutation}

In Kaplan-Meier survival analyses, TERTp mutation was found to be statistically associated with shorter DFS rates than those of TERTp wild-type $(P=0.007)$, whereas no statistical difference was observed for OS between TERTp mutation and TERTp wild-type ( $P=0.983)$ (Fig. 3b, c). We further analyzed the prognostic impact of TERTp mutations on OS and DFS according to HPV status. TERTp mutations were strongly correlated with decreased OS and DFS in patients with HPVnegative TSCCs $(P=0.005$ and $P=0.018$, respectively $)$ (Fig. 3d, e). However, there were no prognostic correlations of TERTp mutations with OS or DFS TERTp mutations in patients with HPV-positive TSCCs $(P=0.202$ and $P=$ 0.904, respectively) (Fig. 3f, g).

We analyzed the OS and DFS through univariate and multivariate analyses (Table 2). In the univariate analyses, older age $(P=0.006)$, higher $\mathrm{T}$ category $(P=0.007)$, and base of tongue (BOT) invasion $(P=0.015)$ were associated with shorter OS rates, while TERTp mutation $(P=0.007)$, higher 

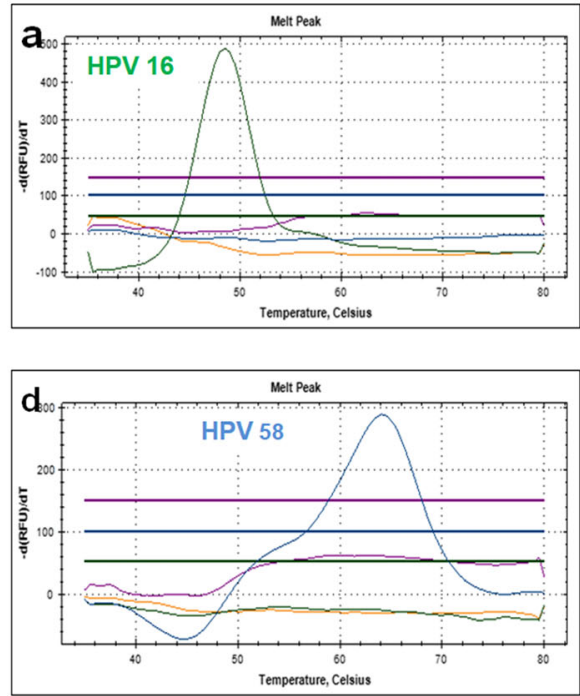

f

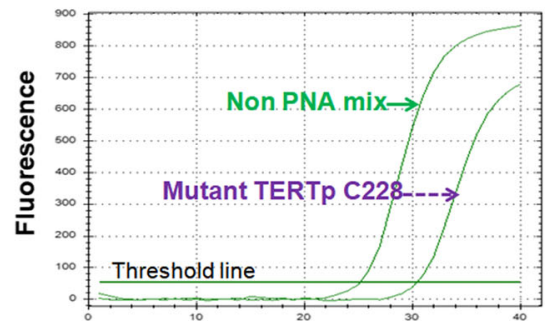

Fig. 2 (a-c) HPV genotypes detected in tonsillar squamous cell carcinomas: HPV 16 (a), concurrent HPV 16 and HPV 18 (b), and HPV 18 (c). d HPV-negative tonsil cancers. e The periodic incidence of HPV in tonsillar squamous cell carcinomas during 20 years. f PNA clamp

T category $(P=0.004)$, BOT invasion $(P=0.002)$, and soft palate invasion $(P=0.005)$ were associated with shorter DFS rates. Multivariate analyses confirmed that older age and higher $\mathrm{T}$ category were independent negative prognostic factors for shorter OS in patients with TSCCs $(P<0.001$, HR: 4.467, 95\% CI: $2.037-9.793 ; P=0.016$, HR: $3.152,95 \%$ CI: 1.244-7.988, respectively). TERTp mutation was identified to be the only independent prognostic factor for DFS in tonsil cancers $(P=0.021$, HR: $3.216,95 \%$ CI: $1.197-8.644)$.

\section{Discussion}

In the present study, the new staging system improved stratification of early and advanced stages and between $\mathrm{T}$ or $\mathrm{N}$ category concerning overall survival based on Korean population. Under the new AJCC 8th edition, the prognostic implication of TERTp mutation in tonsil cancers has been rarely reported. Applying the new AJCC 8th edition, we confirmed the negative prognostic impact of TERTp mutation on survival of surgically managed tonsil cancers staged with the new

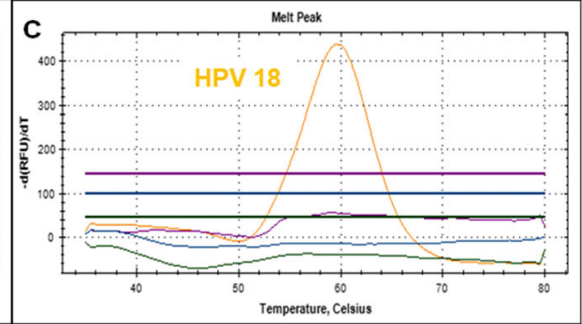

HPV-positive rate during 20 years

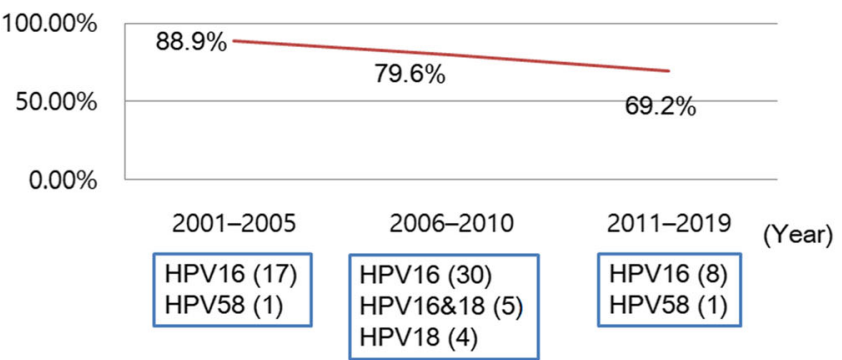

g TERTp mutation (direct sequencing ) c.-124 C > T (p.C228T)

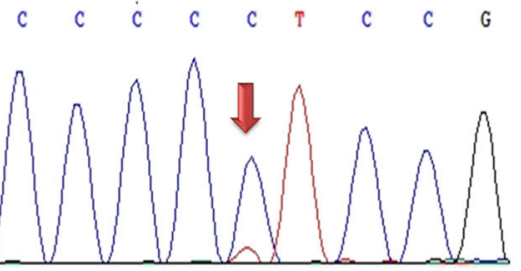

real-time PCR detected TERTp mutation on $\mathrm{C} 228$ in tonsillar squamous cell carcinomas. $\mathrm{g}$ Sequence chromatography demonstrated TERTp c.$124 \mathrm{C}>\mathrm{T}$ (p. C228T) mutation

AJCC 8th edition, especially on HPV-negative TSCCs. TERTp mutation has been reported as a predictor of poor prognosis in laryngeal cancers but not in oral SCCs [17, 25]. A meta-analysis based on published articles concluded that TERTp mutation serves as an adverse prognostic factor in any cancer regardless of organ [26]. Overexpression of TERT by its promoter mutation representing late events of the oncogenic process may increase the self-renewal capacity of cancer stem cells and induce poor clinical outcomes [27, 28]. The non-canonical functions of TERTp mutation might biologically sustain how TERTp mutation is related to poor prognosis.

Vinagre et al. [29] divided various tumors into those with a high frequency of mutations ( $\geq 5 \%$ ) and tumors with no mutations or with a very low frequency of TERTp mutations (< $5 \%$ ) because mutations affecting the telomerase coding region are very uncommon in the cancer setting [11]. We observed 7.5\% TERTp mutation in TSCCs, which is a relatively high frequency according to Vinagre et al. [29]. The frequency of TERTp mutation is variable in head and neck SCCs, which could be because the TERTp mutation can also result from 
Table 1 Association between HPV and TERTp mutation and patient characteristics

\begin{tabular}{|c|c|c|c|c|c|c|c|}
\hline \multirow[t]{2}{*}{ Parameter } & \multirow{2}{*}{$\begin{array}{l}\text { Total } \\
N=80(\%)\end{array}$} & \multicolumn{3}{|l|}{ HPV } & \multicolumn{3}{|l|}{ TERTp } \\
\hline & & $\begin{array}{l}\text { Positive } \\
n=64(80.0 \%)\end{array}$ & $\begin{array}{l}\text { Negative } \\
n=16(20.0 \%)\end{array}$ & $P$ & $\begin{array}{l}\text { Mutated } \\
n=6(7.5 \%)\end{array}$ & $\begin{array}{l}\text { Wildtype } \\
n=74(92.5 \%)\end{array}$ & $P$ \\
\hline Sex & & & & 1.000 & & & 1.000 \\
\hline Male & $70(87.5)$ & $56(87.5)$ & $14(87.5)$ & & $6(100)$ & $64(86.5)$ & \\
\hline Female & $10(12.5)$ & $8(12.5)$ & $2(12.5)$ & & $0(0)$ & $10(13.5)$ & \\
\hline Age (year) & & & & $0.010 *$ & & & 1.000 \\
\hline$\leq 60$ & $52(65.0)$ & 46 (71.9) & $6(37.5)$ & & $4(66.7)$ & $48(64.9)$ & \\
\hline$>60$ & $28(35.0)$ & $18(28.1)$ & $10(62.5)$ & & $2(33.3)$ & $26(35.1)$ & \\
\hline Smoking & & & & 0.263 & & & 0.392 \\
\hline Light & $33(41.3)$ & $32(50.0)$ & $5(31.2)$ & & $1(16.7)$ & $32(43.2)$ & \\
\hline Heavy & $47(58.7)$ & $32(50.0)$ & $11(68.8)$ & & $5(83.3)$ & $42(56.8)$ & \\
\hline Alcohol & & & & $0.021 *$ & & & 0.667 \\
\hline Light & $50(62.5)$ & $44(68.8)$ & $6(37.5)$ & & $3(50.0)$ & $47(63.5)$ & \\
\hline Heavy & $30(37.5)$ & $20(31.2)$ & $10(62.5)$ & & $3(50.0)$ & $27(36.5)$ & \\
\hline Tumor location & & & & 0.173 & & & 0.651 \\
\hline Right side & 47 (58.7) & $40(62.5)$ & $7(43.8)$ & & $3(50.0)$ & $44(59.5)$ & \\
\hline Left side & $33(41.3)$ & $24(37.5)$ & $9(56.2)$ & & $3(50.0)$ & $30(40.5)$ & \\
\hline pT category & & & & 0.088 & & & 0.556 \\
\hline T1-T2 & $49(61.3)$ & $36(56.3)$ & $13(81.3)$ & & $3(50.0)$ & $46(62.2)$ & \\
\hline T3-T4 & $31(38.7)$ & $28(43.7)$ & $3(18.7)$ & & $3(50.0)$ & $28(37.8)$ & \\
\hline pNodal status & & & & $<0.001 *$ & & & 0.333 \\
\hline N0 & $17(21.3)$ & $8(12.5)$ & $9(56.2)$ & & $0(0)$ & $17(23.0)$ & \\
\hline N1-3 & 63 (78.7) & $56(87.5)$ & $7(43.8)$ & & $6(100)$ & $57(77.0)$ & \\
\hline pAJCC stage (8th) & & & & $0.020 *$ & & & 0.624 \\
\hline I-III & $60(75.0)$ & $52(81.2)$ & $8(50.0)$ & & $4(66.7)$ & $56(75.7)$ & \\
\hline IV & $20(25.0)$ & $12(18.8)$ & $8(50.0)$ & & $2(33.3)$ & $18(24.3)$ & \\
\hline HPV status & & & & - & & & 1.000 \\
\hline Positive & $64(80.0)$ & - & - & & $5(83.3)$ & $59(79.7)$ & \\
\hline Negative & $16(20.0)$ & - & - & & $1(16.7)$ & $15(20.3)$ & \\
\hline BOT invasion & & & & 0.263 & & & 0.407 \\
\hline Present & $43(53.8)$ & $32(50.0)$ & $5(31.2)$ & & $4(66.7)$ & $33(44.6)$ & \\
\hline Absent & $37(46.2)$ & $32(50.0)$ & $11(68.8)$ & & $2(33.3)$ & $41(55.4)$ & \\
\hline Soft palate invasion & & & & 0.154 & & & 0.423 \\
\hline Present & $28(35.0)$ & $25(39.1)$ & $3(18.7)$ & & $3(50.0)$ & $25(33.8)$ & \\
\hline Absent & $52(65.0)$ & $39(60.9)$ & $13(81.3)$ & & $3(50.0)$ & $49(66.2)$ & \\
\hline Ipsilateral LN meta & & & & $0.004 *$ & & & 1.000 \\
\hline Present & $58(72.5)$ & $51(79.7)$ & $7(43.8)$ & & $5(83.3)$ & $53(71.6)$ & \\
\hline Absent & $22(27.5)$ & $13(20.3)$ & $9(56.2)$ & & $1(16.7)$ & $21(28.4)$ & \\
\hline Contralateral LN meta & & & & 1.000 & & & 1.000 \\
\hline Present & $12(15.0)$ & $10(15.6)$ & $2(12.5)$ & & $1(16.7)$ & $11(14.9)$ & \\
\hline Absent & $68(85.0)$ & $54(84.4)$ & $14(87.5)$ & & $5(83.3)$ & $63(85.1)$ & \\
\hline ENE & & & & 0.485 & & & 0.409 \\
\hline Present & $51(63.8)$ & $42(65.6)$ & $9(56.2)$ & & $5(83.3)$ & $46(62.2)$ & \\
\hline Absent & $29(36.2)$ & $22(34.4)$ & $7(43.8)$ & & $1(16.7)$ & $28(37.8)$ & \\
\hline
\end{tabular}

$H P V$ human papillomavirus, $p$ pathologic, $L N$ lymph node, BOT base of tongue, AJCC American Joint Committee on Cancer, ENE extranodal extension * Statistically significant, $P<0.05$ 
Fig. 3 a Representative $H \& E$ images according to HPV and TERTp mutation (magnifications, $\times 200)$. TERTp mutation is not related to overall survival (b), whereas it has a strong prognostic impact on shorter disease-free survival (c). In HPV-negative tumors, TERTp mutation is associated with worse overall survival (d) and disease-free survival (e). However, there are no survival correlations in terms of overall (f) and disease-free (g) survivals in HPV-positive tumors
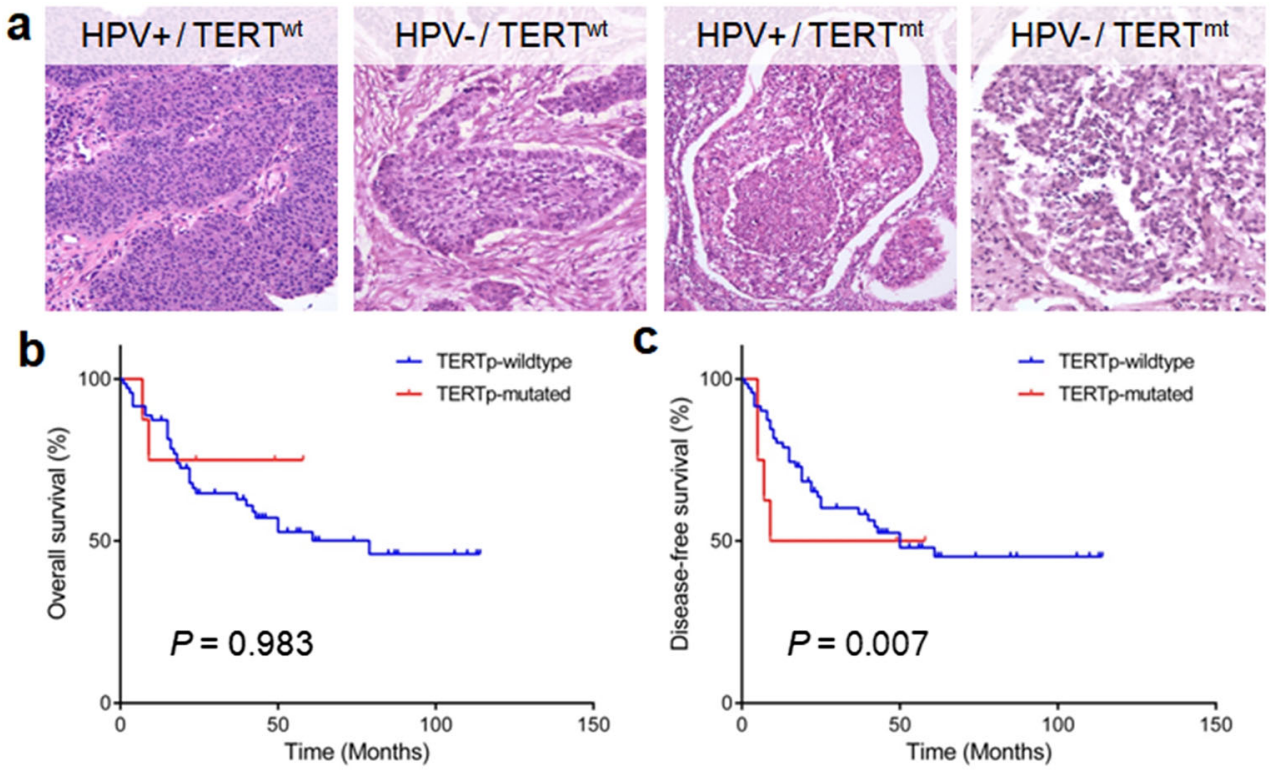

C

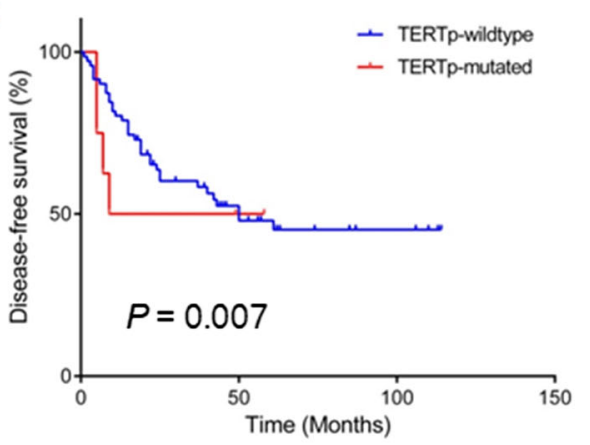

HPV-negative TSCC
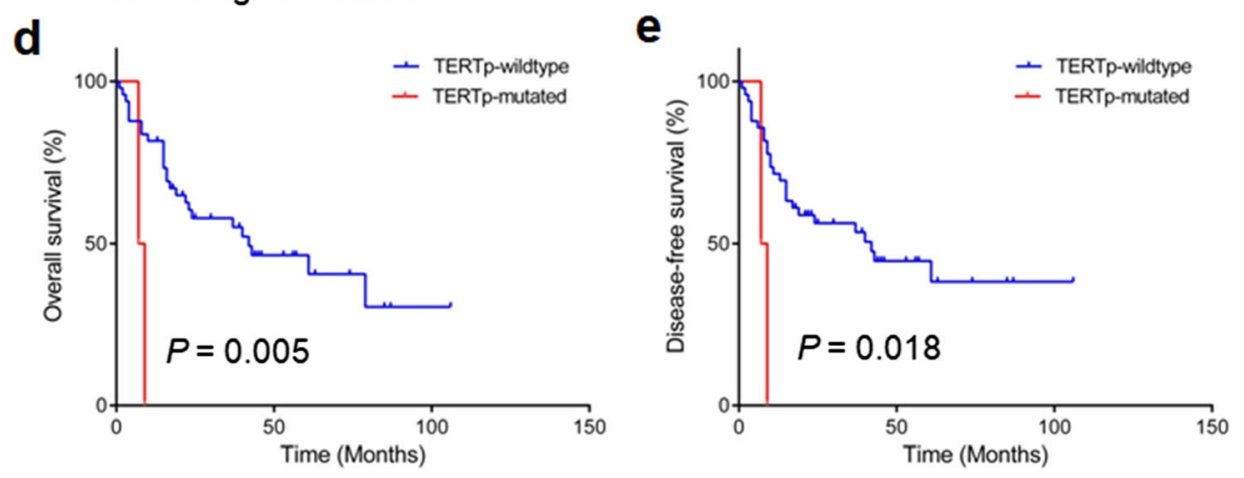

HPV-positive TSCC
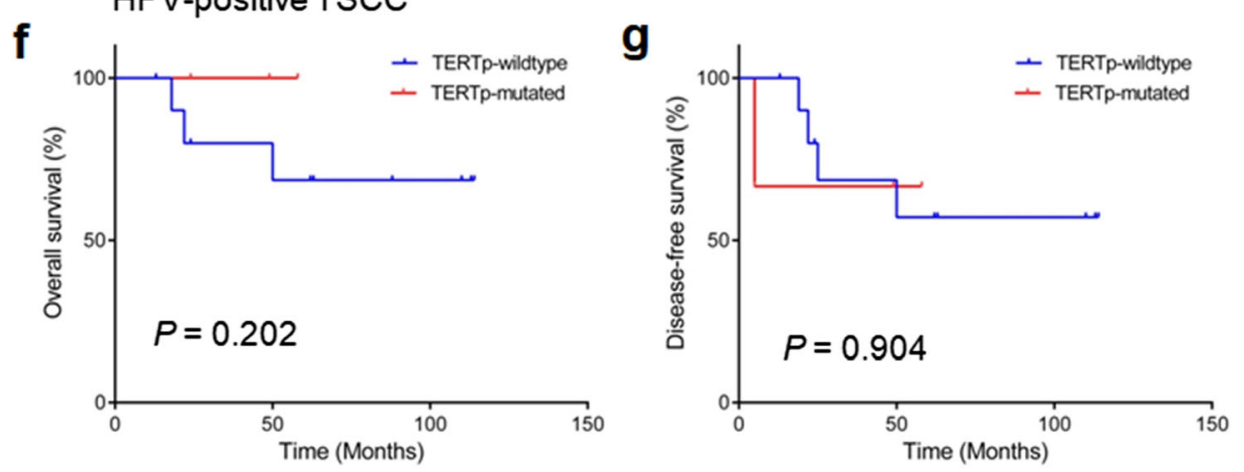

environmental factors such as ultraviolet radiation and chemical carcinogens $[29,30]$. Thus, oral cavity SCCs have a wide range of the frequency of $0-65 \%$ for the TERTp mutation [14, $17,22,23]$; this mutation is also common for tongue area $(63.6 \%)$ and laryngeal SCCs $(27 \%)[22,25]$.

The lack of specific clinicodemographic features related to TERTp mutation, found in the present study, has been mainly described in SCCs in head and neck or other sites including skin, lung, and uterine cervix $[14,22,25,31]$. The majority (83.3\%) of TERTp mutations occurred exclusively in the HPV16-positive TSCCs, although there was no statistical association between TERTp mutation and HPV. The considerable presence of TERTp mutation in HPV-positive tumors but a lack of statistical association between them have been previously described in the oral, oropharyngeal, and uterine cervical cancers, where all HPV16-positive oral SCCs and 70\% 
Table 2 Univariate and multivariate analyses of overall survival and disease-free survival of patients with tonsillar squamous cell carcinoma by univariate and multivariate analyses

\begin{tabular}{|c|c|c|c|c|c|c|c|c|}
\hline & \multicolumn{4}{|l|}{ Overall survival } & \multicolumn{4}{|c|}{ Disease-free survival } \\
\hline & \multicolumn{2}{|l|}{ Univariate } & \multicolumn{2}{|l|}{ Multivariate } & \multicolumn{2}{|l|}{ Univariate } & \multicolumn{2}{|l|}{ Multivariate } \\
\hline & $\mathrm{HR}(95 \% \mathrm{CI})$ & $P$ & HR $(95 \%$ CI) & $P$ & $\mathrm{HR}(95 \% \mathrm{CI})$ & $P$ & HR $(95 \%$ CI) & $P$ \\
\hline $\begin{array}{l}\text { TERTp } \\
\text { Wildtype vs. mutated }\end{array}$ & $\begin{array}{l}0.984 \\
(0.234-4.146)\end{array}$ & 0.983 & & & $\begin{array}{l}3.879 \\
(1.449-10.388)\end{array}$ & $0.007 *$ & $\begin{array}{l}3.216 \\
(1.197-8.644)\end{array}$ & $0.021 *$ \\
\hline $\begin{array}{l}\text { HPV } \\
\text { Absent vs. present }\end{array}$ & $\begin{array}{l}0.580 \\
(0.255-1.321)\end{array}$ & 0.195 & & & $\begin{array}{l}0.802 \\
(0.377-1.707)\end{array}$ & 0.567 & & \\
\hline $\begin{array}{l}\text { Sex } \\
\text { Male vs. female }\end{array}$ & $\begin{array}{l}0.454 \\
(0.108-1.910)\end{array}$ & 0.282 & & & $\begin{array}{l}0.719 \\
(0.255-2.029)\end{array}$ & 0.533 & & \\
\hline $\begin{array}{l}\text { Age (year) } \\
<60 \text { vs. } \geq 60\end{array}$ & $\begin{array}{l}2.744 \\
(1.327-5.674)\end{array}$ & $0.006^{*}$ & $\begin{array}{l}4.467 \\
(2.037-9.793)\end{array}$ & $<0.001^{*}$ & $\begin{array}{l}1.813 \\
(0.943-3.488)\end{array}$ & 0.075 & & \\
\hline $\begin{array}{c}\text { Tonsil side } \\
\text { Rt vs. Lt }\end{array}$ & $\begin{array}{l}1.396 \\
(0.680-2.863)\end{array}$ & 0.363 & & & $\begin{array}{l}0.917 \\
(0.478-1.758)\end{array}$ & 0.794 & & \\
\hline $\begin{array}{l}\text { Alcohol } \\
\text { Light vs. heavy }\end{array}$ & $\begin{array}{l}1.371 \\
(0.663-2.834)\end{array}$ & 0.394 & & & $\begin{array}{l}1.064 \\
(0.554-2.045)\end{array}$ & 0.852 & & \\
\hline $\begin{array}{l}\text { Smoking } \\
\text { Light vs. heavy }\end{array}$ & $\begin{array}{l}1.853 \\
(0.878-3.908)\end{array}$ & 0.105 & & & $\begin{array}{l}1.358 \\
(0.712-2.591)\end{array}$ & 0.353 & & \\
\hline $\begin{array}{l}\text { pT category } \\
\text { T1-2 vs. T3-4 }\end{array}$ & $\begin{array}{l}2.745 \\
(1.321-5.708)\end{array}$ & $0.007 *$ & $\begin{array}{l}3.152 \\
(1.244-7.988)\end{array}$ & $0.016^{*}$ & $\begin{array}{l}2.549 \\
(1.340-4.850)\end{array}$ & $0.004 *$ & $\begin{array}{l}1.556 \\
(0.725-3.341)\end{array}$ & 0.257 \\
\hline $\begin{array}{l}\text { pN category } \\
\text { N0 vs. N1-3 }\end{array}$ & $\begin{array}{l}2.651 \\
(0.801-8.773)\end{array}$ & 0.110 & & & $\begin{array}{l}2.821 \\
(0.998-7.968)\end{array}$ & 0.050 & & \\
\hline $\begin{array}{l}\text { BOT invasion } \\
\text { Absent vs. present }\end{array}$ & $\begin{array}{l}2.579 \\
(1.206-5.513)\end{array}$ & $0.015^{*}$ & $\begin{array}{l}1.770 \\
(0.707-4.426)\end{array}$ & 0.222 & $\begin{array}{l}2.951 \\
(1.504-5.791)\end{array}$ & $0.002 *$ & $\begin{array}{l}1.823 \\
(0.790-4.206)\end{array}$ & 0.159 \\
\hline $\begin{array}{l}\text { Soft palate invasion } \\
\text { Absent vs. present }\end{array}$ & $\begin{array}{l}1.775 \\
(0.867-3.630)\end{array}$ & 0.116 & & & $\begin{array}{l}2.513 \\
(1.323-4.771)\end{array}$ & $0.005^{*}$ & $\begin{array}{l}1.445 \\
(0.662-3.156)\end{array}$ & 0.356 \\
\hline
\end{tabular}

$H R$ hazard ratio, $C I$ confidence interval, $H P V$ human papillomavirus, $R t$ right, $L t$ left, $p$ pathologic, BOT base of tongue

*Statistically significant, $P$ value $<0.05$

of HPV-positive uterine cervical cancers harbored TERTp mutations $[14,22]$. Some previous studies assumed that HPVinduced TERTp activations would be functionally different from the consequences of TERTp mutation in the absence of HPV [11, 18-20].

This study thoroughly investigated HPV status and genotypes in clinical specimens and stratified patients according to HPV status, with long-term follow-up data. In the present study, only high-risk HPV was dominated $(80 \%)$ with the majority (92.2\%) of HPV16. High-risk HPVs are the cause of approximately $31 \%$ of oropharyngeal SCCs $[2,9]$. The prevalence of HPV infections in TSCCs is $37-80 \%$ in western countries and 35-73\% in Korea [3, 7, 21, 32, 33].

HPV16 is the dominant virus in oropharyngeal SCC accounting for $82-87 \%$ of all HPV-positive cases [9]. The fraction of oropharyngeal cancer attributable to HPV is similarly the highest (>40\%) in developed countries including Europe, North America, Australia, New Zealand, Japan, and Republic of Korea [9, 34]. HPV infection was not an independent prognostic factor for OS and DFS in the 8th edition in the present study, which may be because of the incorporation of HPV into $\mathrm{T}$ and $\mathrm{N}$ categories of the staging system, and the effect of HPV might have been overshadowed by the impact of the staging modification because our study analyzed all together with HPV-positive and HPV-negative tumors.

In conclusion, the present study reveals that the TERTp mutation is present in a subpopulation of patients with TSCC and emphasizes the negative prognostic impact of TERTp mutation in tonsil cancers under the newly 8 th edition of the AJCC staging system for oropharyngeal cancers, especially on HPV-negative TSCCs. This may be utilized to determine clinical aggressiveness of TSCCs.

Author Contributions MJK and HK designed the study, interpreted the data, wrote the manuscript, and drafted of the manuscript; ESN, SJC, K$\mathrm{WM}$, and $\mathrm{MH}$ participated in study coordination and pathologic data analysis; BP, HGC, ESK, HSH, TK, and HJK collected clinical samples and analyzed clinical data. All authors read and approved the final manuscript. 
Funding This research was supported by the Hallym University Research Fund (HURF-2018-64) and the Basic Science Research Program through the National Research Foundation of Korea funded by the Ministry of Science and ICT of Korea government (NRF2019R1C1C1004463) granted to MJ Kwon.

Data Availability The data used to support the findings of this study are available from the corresponding author upon request.

\section{Compliance with Ethical Standards}

\section{Declarations Not applicable.}

Conflict of Interest The authors declare that they have no conflict of interest.

Ethics Approval The surgical materials were collected and used according to the instructions of Kangdong Sacred-Heart Hospital Institutional Ethics Committee (No. 14-2-57). Specimens and data were stored anonymously.

Consent to Participate Informed consent was obtained from all individual participants included in the study.

Consent for Publication Additional informed consent was obtained from all individual participants for whom identifying information is included in this article.

Open Access This article is licensed under a Creative Commons Attribution 4.0 International License, which permits use, sharing, adaptation, distribution and reproduction in any medium or format, as long as you give appropriate credit to the original author(s) and the source, provide a link to the Creative Commons licence, and indicate if changes were made. The images or other third party material in this article are included in the article's Creative Commons licence, unless indicated otherwise in a credit line to the material. If material is not included in the article's Creative Commons licence and your intended use is not permitted by statutory regulation or exceeds the permitted use, you will need to obtain permission directly from the copyright holder. To view a copy of this licence, visit http://creativecommons.org/licenses/by/4.0/.

\section{References}

1. El-Naggar AK, JKC C, Rubin Grandis J, Takata T, Slootweg PJ, International Agency for Research on Cancer (2017) WHO classification of head and neck tumours. International Agency for Research on Cancer, Lyon

2. Taberna M, Mena M, Pavon MA, Alemany L, Gillison ML, Mesia R (2017) Human papillomavirus-related oropharyngeal cancer. Ann Oncol 28(10):2386-2398

3. Luginbuhl A, Sanders M, Spiro JD (2009) Prevalence, morphology, and prognosis of human papillomavirus in tonsillar cancer. Ann Otol Rhinol Laryngol 118(10):742-749

4. Kuo YY, Chu PY, Chang SY, Wang YF, Tsai TL, Yang MH, Wang LW, Tai SK (2013) Treatment selection for tonsillar squamous cell carcinoma. J Chin Med Assoc 76(4):211-217

5. Olaleye O, Moorthy R, Lyne O, Black M, Mitchell D, Wiseberg J A 20-year retrospective study of tonsil cancer incidence and survival trends in South East England: 1987-2006. Clin Otolaryngol 36(4): $325-335$
6. Amin MB, American Joint Committee on Cancer., American Cancer Society (2017) AJCC cancer staging manual. 8th Edition, American Joint Committee on Cancer, Springer: Chicago IL

7. Song JS, Kim MS, Park JW, Lee YS, Kang CS (2012) Expression of human papillomavirus-related proteins and its clinical implication in tonsillar squamous cell carcinoma. Korean J Pathol 46(2): 177-186

8. Park K, Cho KJ, Lee M, Yoon DH, Kim J, Kim SY, Nam SY, Choi SH, Roh JL, Han MW, Lee SW, Song SY, Back JH, Kim SB (2013) p16 immunohistochemistry alone is a better prognosticator in tonsil cancer than human papillomavirus in situ hybridization with or without p16 immunohistochemistry. Acta Otolaryngol 133(3):297-304

9. de Martel C, Plummer M, Vignat J, Franceschi S (2017) Worldwide burden of cancer attributable to HPV by site, country and HPV type. Int J Cancer 141(4):664-670

10. Kim HS, Kwon MJ, Song JH, Kim ES, Kim HY, Min KW (2018) Clinical implications of TERT promoter mutation on IDH mutation and MGMT promoter methylation in diffuse gliomas. Pathol Res Pract 214(6):881-888

11. Aubert G, Lansdorp PM (2008) Telomeres and aging. Physiol Rev 88(2):557-579

12. Arita H, Narita Y, Takami H, Fukushima S, Matsushita Y, Yoshida A, Miyakita Y, Ohno M, Shibui S, Ichimura K (2013) TERT promoter mutations rather than methylation are the main mechanism for TERT upregulation in adult gliomas. Acta Neuropathol 126(6): 939-941

13. Dogan S, Xu B, Middha S, Vanderbilt CM, Bowman AS, Migliacci J, Morris LGT, Seshan VE, Ganly I (2019) Identification of prognostic molecular biomarkers in 157 HPV-positive and HPVnegative squamous cell carcinomas of the oropharynx. Int $\mathrm{J}$ Cancer 145:3152-3162

14. Vinothkumar V, Arunkumar G, Revathidevi S, Arun K, Manikandan M, Rao AK, Rajkumar KS, Ajay C, Rajaraman R, Ramani R, Murugan AK, Munirajan AK (2016) TERT promoter hot spot mutations are frequent in Indian cervical and oral squamous cell carcinomas. Tumour Biol 37(6):7907-7913

15. Ghantous Y, Bahouth Z, Abu El-Naaj I (2018) Clinical and genetic signatures of local recurrence in oral squamous cell carcinoma. Arch Oral Biol 95:141-148

16. Barczak W, Suchorska WM, Sobecka A, Bednarowicz K, Machczynski P, Golusinski P, Rubis B, Masternak MM, Golusinski W (2017) hTERT C250T promoter mutation and telomere length as a molecular markers of cancer progression in patients with head and neck cancer. Mol Med Rep 16(1):441-446

17. Chang KP, Wang CI, Pickering CR, Huang Y, Tsai CN, Tsang NM, Kao HK, Cheng MH, Myers JN (2017) Prevalence of promoter mutations in the TERT gene in oral cavity squamous cell carcinoma. Head Neck 39(6):1131-1137

18. Liu X, Roberts J, Dakic A, Zhang Y, Schlegel R (2008) HPV E7 contributes to the telomerase activity of immortalized and tumorigenic cells and augments E6-induced hTERT promoter function. Virology 375(2):611-623

19. Wang HY, Kim G, Cho H, Kim S, Lee D, Park S, Park KH, Lee H (2015) Diagnostic performance of HPV E6/E7, hTERT, and Ki67 mRNA RT-qPCR assays on formalin-fixed paraffin-embedded cervical tissue specimens from women with cervical cancer. Exp Mol Pathol 98(3):510-516

20. Liu X, Dakic A, Chen R, Disbrow GL, Zhang Y, Dai Y, Schlegel R (2008) Cell-restricted immortalization by human papillomavirus correlates with telomerase activation and engagement of the hTERT promoter by Myc. J Virol 82(23):11568-11576

21. Kim SH, Koo BS, Kang S, Park K, Kim H, Lee KR, Lee MJ, Kim JM, Choi EC, Cho NH (2007) HPV integration begins in the tonsillar crypt and leads to the alteration of p16, EGFR and c-myc during tumor formation. Int J Cancer 120(7):1418-1425 
22. Annunziata C, Pezzuto F, Greggi S, Ionna F, Losito S, Botti G, Buonaguro L, Buonaguro FM, Tornesello ML (2018) Distinct profiles of TERT promoter mutations and telomerase expression in head and neck cancer and cervical carcinoma. Int $\mathrm{J}$ Cancer 143(5):1153-1161

23. Boscolo-Rizzo P, Giunco S, Rampazzo E, Brutti M, Spinato G, Menegaldo A, Stellin M, Mantovani M, Bandolin L, Rossi M, Del Mistro A, Tirelli G, Dei Tos AP, Guerriero A, Niero M, Da Mosto MC, Polesel J, De Rossi A (2020) TERT promoter hotspot mutations and their relationship with TERT levels and telomere erosion in patients with head and neck squamous cell carcinoma. J Cancer Res Clin Oncol 146(2):381-389

24. Kwon MJ, Kang SY, Cho H, Lee JI, Kim ST, Suh YL (2019) Clinical relevance of molecular subgrouping of gliomatosis cerebri per 2016 WHO classification: a clinicopathological study of 89 cases. Brain Pathol

25. Qu Y, Dang S, Wu K, Shao Y, Yang Q, Ji M, Shi B, Hou P (2014) TERT promoter mutations predict worse survival in laryngeal cancer patients. Int J Cancer 135(4):1008-1010

26. Yuan P, Cao JL, Abuduwufuer A, Wang LM, Yuan XS, Lv W, Hu J (2016) Clinical characteristics and prognostic significance of TERT promoter mutations in cancer: a cohort study and a metaanalysis. PLoS One 11(1):e0146803

27. Killela PJ, Reitman ZJ, Jiao Y, Bettegowda C, Agrawal N, Diaz LA Jr, Friedman AH, Friedman H, Gallia GL, Giovanella BC, Grollman AP, He TC, He Y, Hruban RH, Jallo GI, Mandahl N, Meeker AK, Mertens F, Netto GJ, Rasheed BA, Riggins GJ, Rosenquist TA, Schiffman M, Shih Ie M, Theodorescu D, Torbenson MS, Velculescu VE, Wang TL, Wentzensen N, Wood LD, Zhang M, McLendon RE, Bigner DD, Kinzler KW, Vogelstein B, Papadopoulos N, Yan H (2013) TERT promoter mutations occur frequently in gliomas and a subset of tumors derived from cells with low rates of self-renewal. Proc Natl Acad Sci U S A 110(15):60216026
28. Jeong DE, Woo SR, Nam H, Nam DH, Lee JH, Joo KM (2017) Preclinical and clinical implications of TERT promoter mutation in glioblastoma multiforme. Oncol Lett 14(6):8213-8219

29. Vinagre J, Pinto V, Celestino R, Reis M, Populo H, Boaventura P, Melo M, Catarino T, Lima J, Lopes JM, Maximo V, SobrinhoSimoes M, Soares P (2014) Telomerase promoter mutations in cancer: an emerging molecular biomarker? Virchows Arch 465(2): $119-133$

30. Populo H, Boaventura P, Vinagre J, Batista R, Mendes A, Caldas R, Pardal J, Azevedo F, Honavar M, Guimaraes I, Manuel Lopes J, Sobrinho-Simoes M, Soares P (2014) TERT promoter mutations in skin cancer: the effects of sun exposure and $\mathrm{X}$-irradiation. J Invest Dermatol 134(8):2251-2257

31. Ma X, Gong R, Wang R, Pan Y, Cai D, Pan B, Li Y, Xiang J, Li H, Zhang J, Sun Y, Chen H (2014) Recurrent TERT promoter mutations in non-small cell lung cancers. Lung Cancer 86(3):369-373

32. Mellin H, Friesland S, Auer G, Dalianis T, Munck-Wikland E (2003) Human papillomavirus and DNA ploidy in tonsillar cancer-correlation to prognosis. Anticancer Res 23(3C):28212828

33. Lee M, Kim SB, Lee SW, Roh JL, Choi SH, Nam SY, Kim SY, Cho KJ (2013) Human papillomavirus prevalence and cell cycle related protein expression in tonsillar squamous cell carcinomas of Korean patients with clinicopathologic analysis. Korean J Pathol 47(2):148-157

34. Gayatree A, Tanveer N, Arora VK, Arora V (2020) Are histomorphological features predictive of p16 immunopositivity different for oral and oropharyngeal squamous cell carcinoma? Indian Journal of Surgical Oncology 11(2):248-255

Publisher's Note Springer Nature remains neutral with regard to jurisdictional claims in published maps and institutional affiliations. 